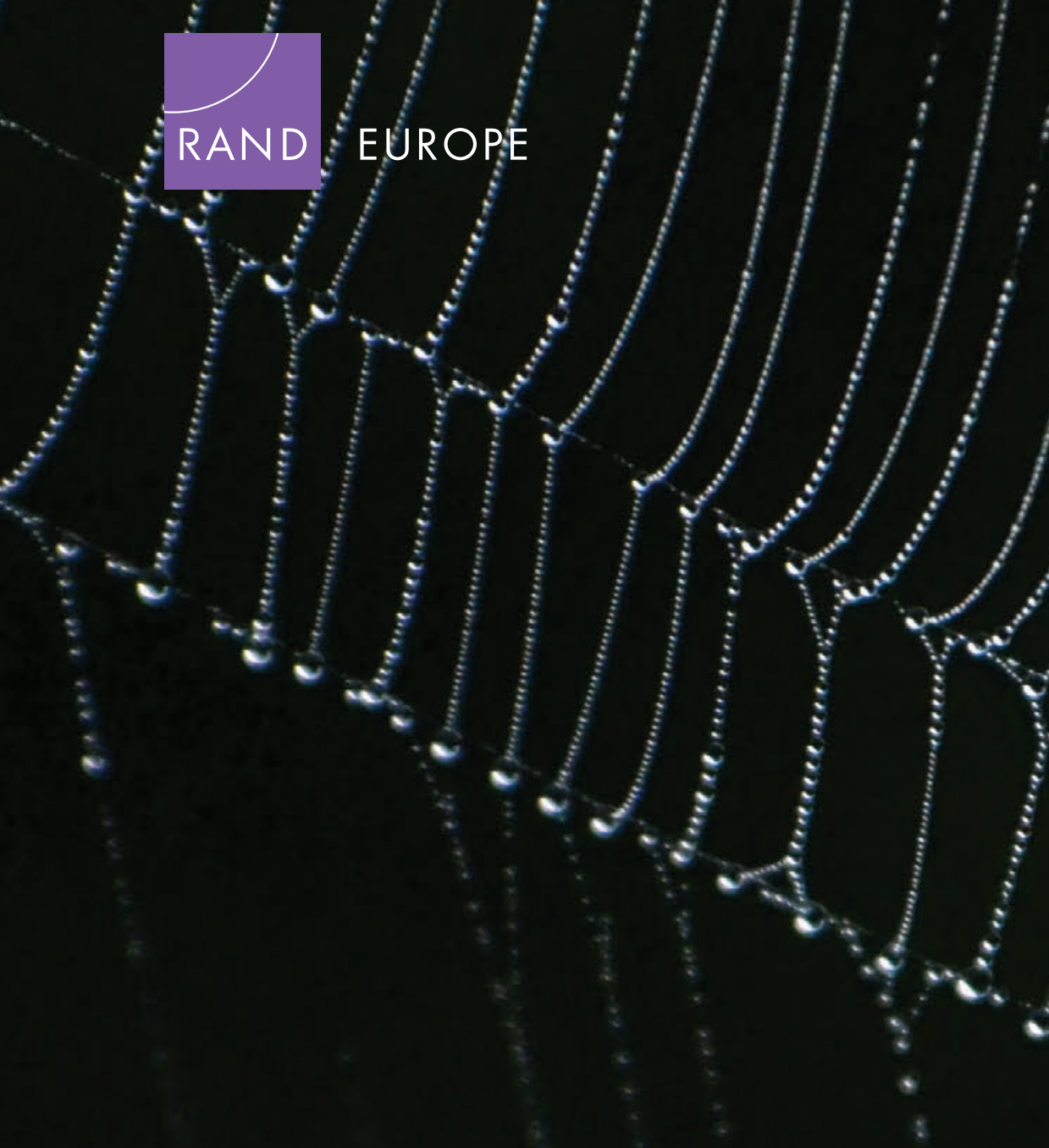

\title{
The role of the
}

\section{'dark web' in the}

\section{trade of illicit drugs}

The Internet has fundamentally changed ways of doing business, including the operations and activities of illegal markets. There are now around 50 online marketplaces on the 'dark web' that trade illegal drugs, novel psychoactive substances (NPS), prescription drugs and other - often illegal - goods and services. These so-called cryptomarkets are accessible with a normal Internet connection, but require special anonymising software to access.

The role of these cryptomarkets in facilitating the trade of illicit drugs was first highlighted by the success of Silk Road, an online marketplace for the sale of illegal goods. Silk Road was taken down by the FBI in October 2013; however, other very similar cryptomarkets filled the void within a matter of weeks.

RAND Europe, in collaboration with researchers from the University of Manchester and the University of Montreal, was commissioned by the Research and Documentation Centre (Wetenschappelijk Onderzoek- en Documentatiecentrum, WODC), the independent research arm of the Ministry of Security and Justice in the Netherlands, to investigate the role of the Internet in facilitating the drugs trade. 


\section{The scope of cryptomarkets selling illicit drugs}

The study considered the trade of illicit drugs online, via both cryptomarkets and normal websites that can be found through search engines like Google, otherwise known as the 'clear net'. The overall aims of the study were to:

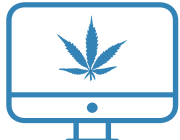

Characterise the scope and size of the sale of illicit drugs online.
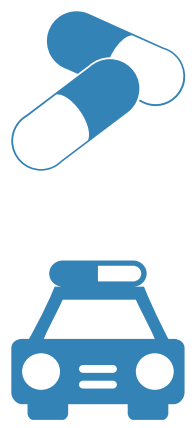

Identify the illicit drugs being sold online and the extent to which they are.

Explore potential avenues for the detection and intervention of websites selling illicit drugs by law enforcement.

A quantitative assessment of the size and scope of the sale of illicit drugs was conducted through the collection and analysis of data and information extracted from eight of the largest cryptomarkets during January 2016. As the data included most drug vendors, listings and transactions, estimations of the total revenue generated should be taken as a lower boundary estimate of trade on these markets. These quantitative findings were then compared and contrasted to findings from the literature, interviews with experts and law enforcement officials, and a focus group with law enforcement representatives.

\section{Key findings}

\section{(\$) Revenues and transactions}

- The number of transactions of illicit drugs on the cryptomarkets has tripled, with revenues doubling, since Silk Road was shut down in 2013. This is despite various law enforcement interventions and exit scams by online marketplaces, which have led to declining levels of trust between buyers and vendors, and less confidence in cryptomarkets.

Yearly revenue by drug type ${ }^{\dagger}(\$)$

\section{$\$ 2,000,000 \quad \$ 1,000,000$}

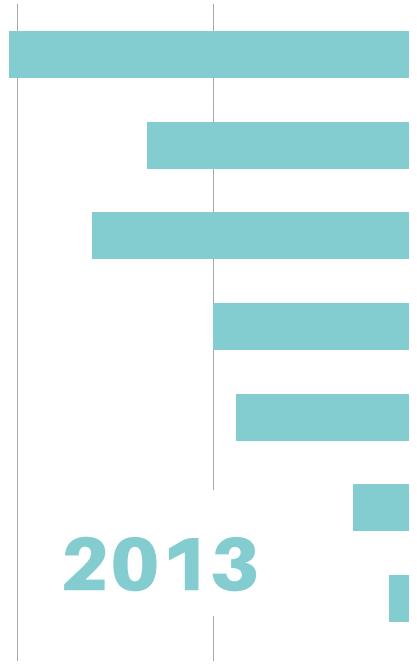

$\$ 1,000,000 \$ 2,000,000 \$ 3,000,000 \$ 4,000,000$

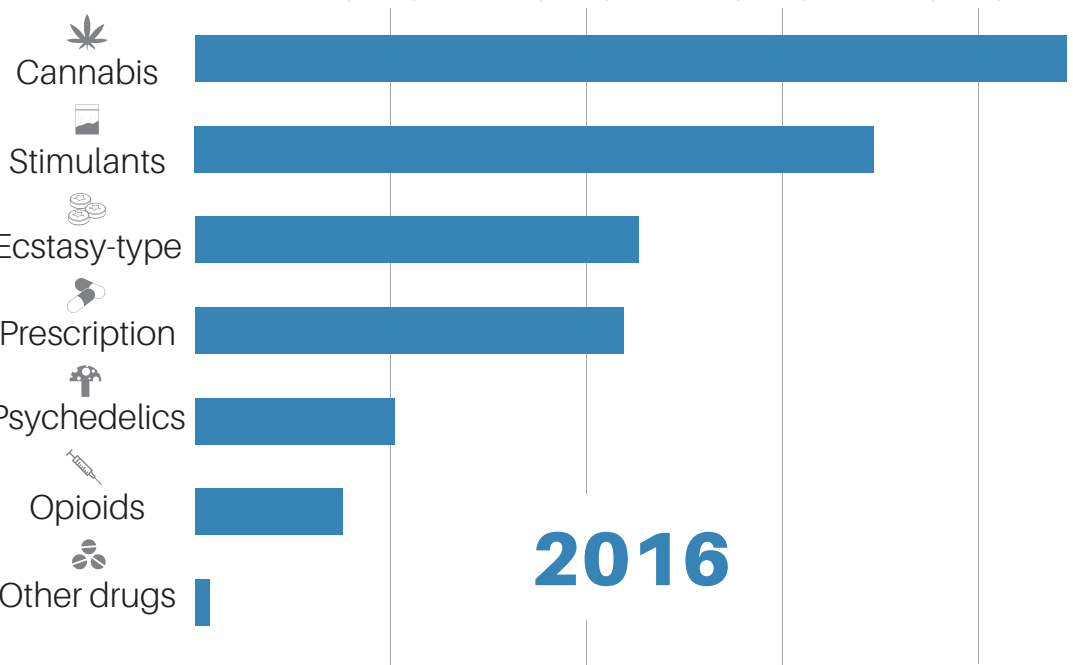


- Total drug revenues on cryptomarkets cryptomarkets (excluding prescription drugs, alcohol and tobacco) during January 2016 were estimated to be between $\$ 12.0(€ 10.5)$ and $\$ 21.1$ ( $€$ 18.5) million*. This suggests that cryptomarkets are only a niche market. According to the European Monitoring Centre for Drugs and Drug Addiction's (EMCDDA) 2016 EU Drug Markets Report, the total offline market for drugs is much larger: an estimated \$2.3 (€2) billion* on average per month for Europe alone.

- The majority of transactions were generated by advertisements ('listings') placed by vendors, and were for values less than $\$ 100(€ 87.72)^{*}$. In these instances, customers are likely buying for their personal use. However, these retail transactions generated only 18 per cent of total revenues. In fact, transactions that are likely purchased by customers with intent to resell (those greater than $\left.\$ 1,000(€ 877.2)^{*}\right)$ generated more of the total revenues, nearly 25 per cent. Based on the extent of wholesale transactions, it is likely that some online buyers are drug dealers sourcing stock intended for offline distribution.

\section{Wholesale transactions and revenue (\%)}

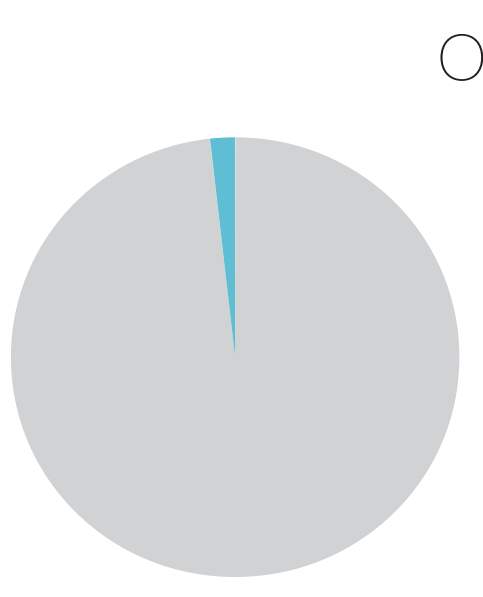

Transactions
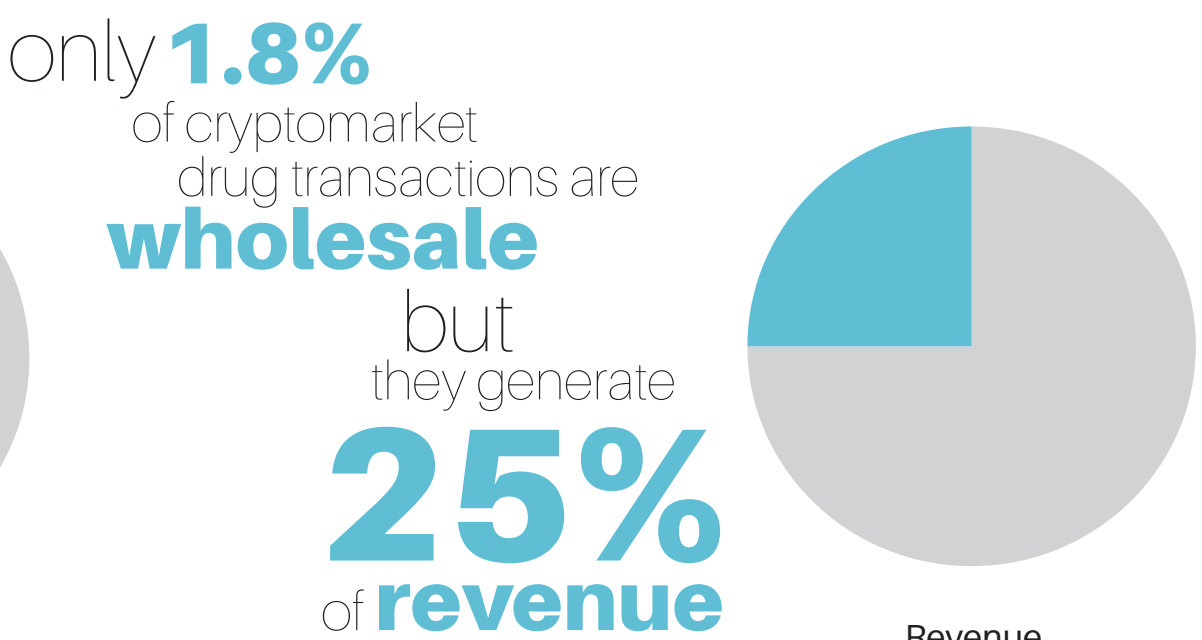

Revenue

\section{The types of drugs sold}

- The illicit drugs sold on cryptomarkets were predominantly cannabis (37 per cent of total revenues), stimulants (cocaine, amphetamines) (29 per cent) and ecstasy-type drugs (19 per cent). These figures are very similar to EMCDDA estimates about drugs sold offline, apart from ecstasy-type drugs (just three per cent of the total European retail drug market) and heroin ( 28 per cent of the total European drug market, but just six per cent of the total drugs sold on cryptomarkets).

- For online markets, the main drugs sold are typically associated with recreational or 'party' use (e.g. cannabis, ecstasy, MDMA). A possible explanation for the differences between 'online' and 'offline' markets may be that cryptomarkets purchases typically require an element of planning, which may not suit the daily use of dependent users of heroin, for example. 


\section{Countries}

- Cryptomarkets appeared to be dominated by vendors from the U.S., Australia, Canada and Western Europe. Vendors who indicated they are operating from the U.S. had the highest market share of drugs (35.9 per cent of total drug revenues), closely followed by the U.K. (16.1 per cent) and Australia (10.6 per cent). The Netherlands had a $\mathbf{7 . 1}$ per cent revenue share, which was less than Germany at 8.4 per cent.

\section{Market share leaders (\%)}

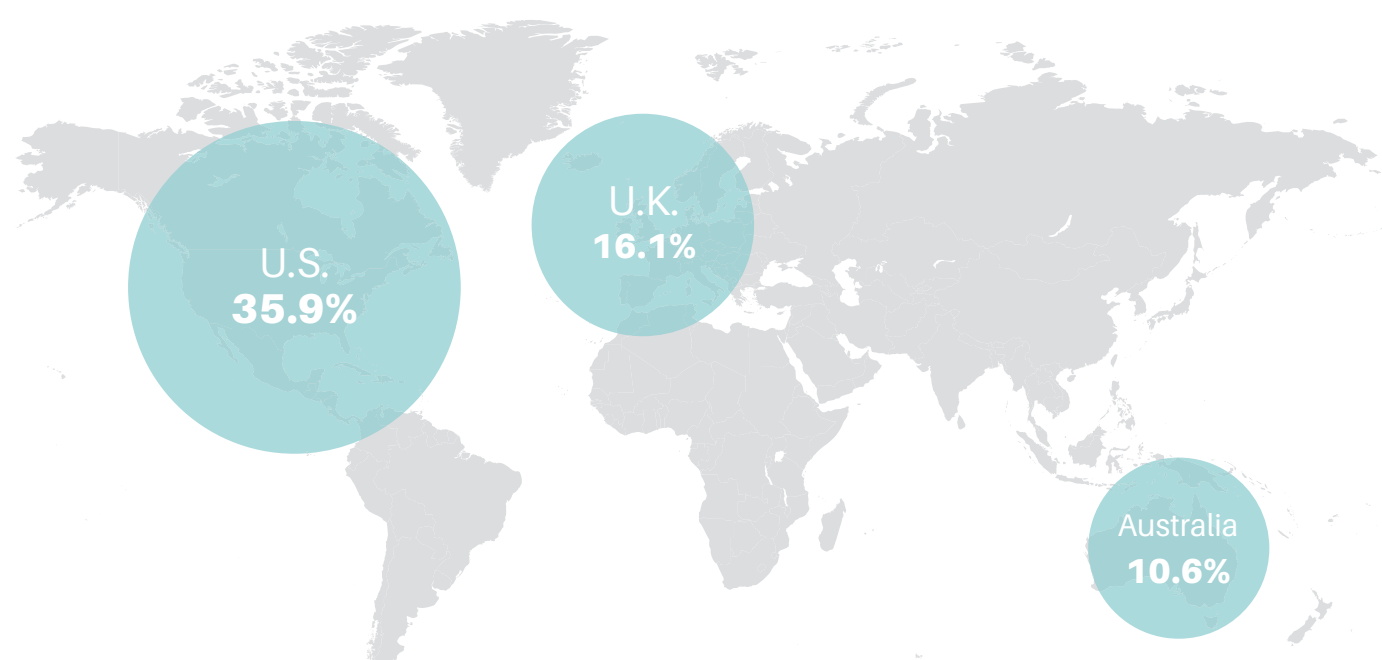

Countries from which vendors operate (monthly revenue)

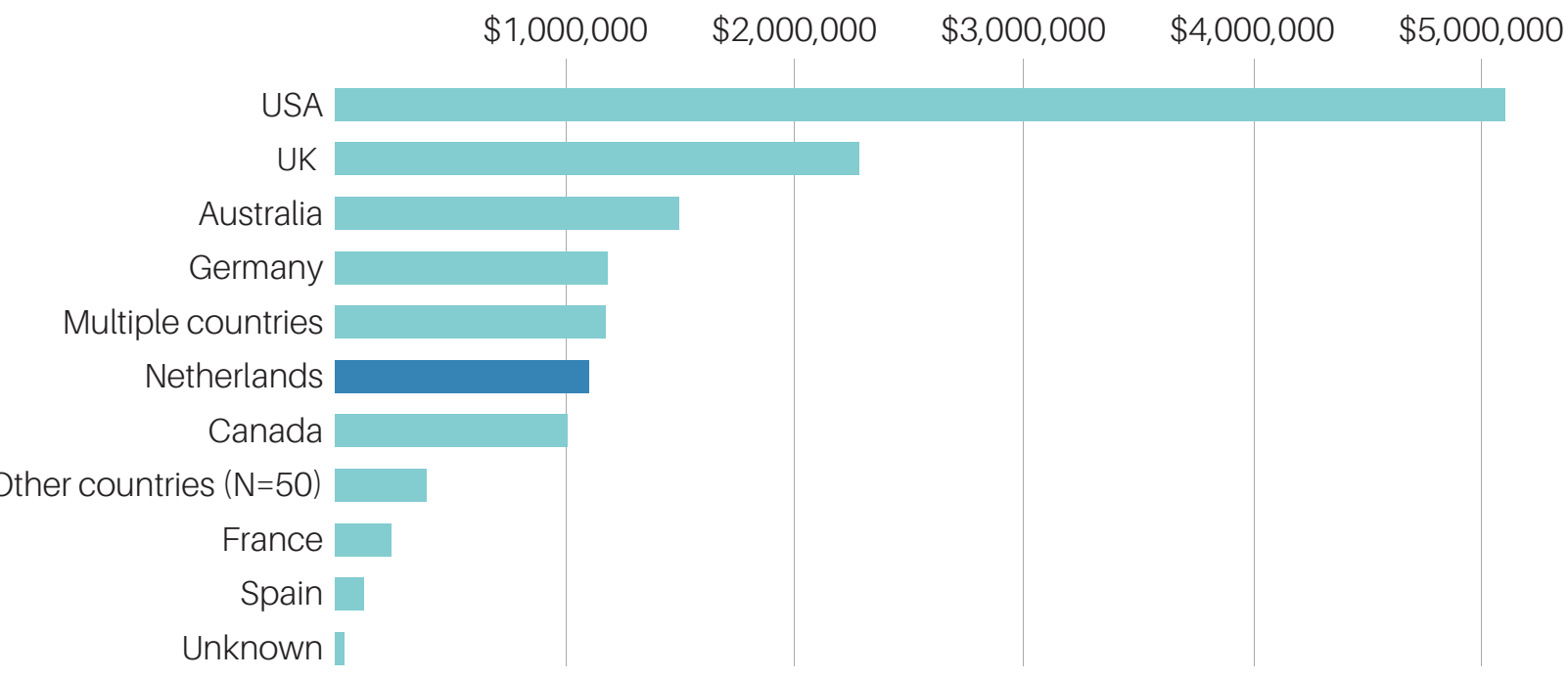


- However, the revenue share from the Netherlands could be underestimated, as there are indications that some Dutch vendors are shipping drugs from locations outside the country. For example, vendors may drive across a border to ship from neighbouring countries, like Germany, so that their shipments evade the additional attention paid by border officials in many countries to Dutch parcel shipments.

- Per capita, the Netherlands had the highest revenues for illicit drug sales on cryptomarkets - Dutch vendors made a total of $\$ \mathbf{1 . 1}$ million ( $€ \mathbf{1 . 0}$ million) ${ }^{*}$. The country dominated sales of MDMA and ecstasy on cryptomarkets - $\mathbf{2 3}$ per cent of total global revenues - but had only two per cent of the global sales of cannabis.

Monthly revenues by drug type ${ }^{\dagger}(\$)$

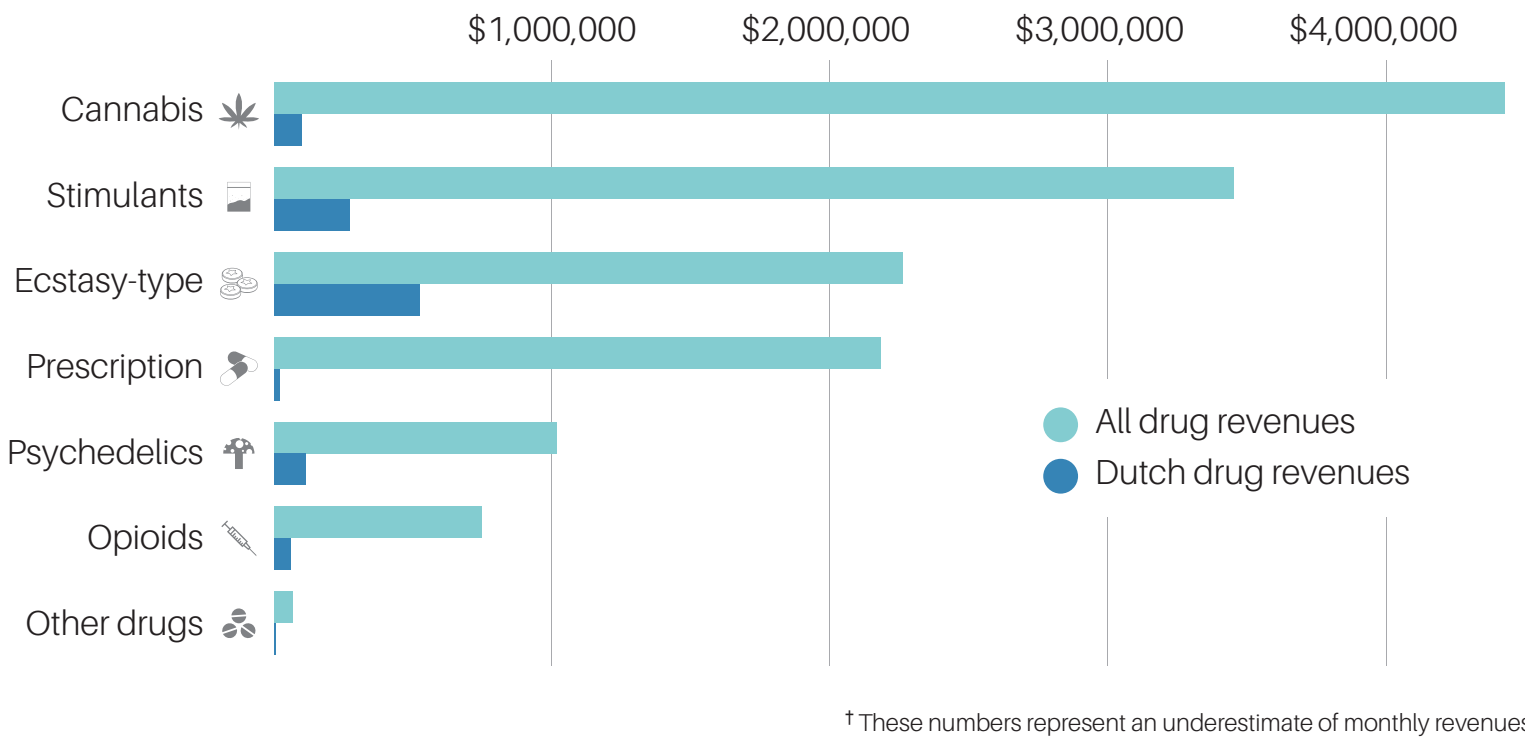

\section{Vendors and buyers}

- Evidence is limited, but both vendors and buyers appeared to be young males from Englishspeaking or Western European countries who are well-educated, entrepreneurial and have strong IT-skills. Vendors also seem to be a mix of professional drug dealers with close ties to production, who consider Internet sales as an additional revenue stream, and 'newbies' who previously only sold drugs to friends.

\section{VENDOR / BUYER PROFILE}

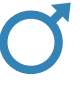

Young male 
- The majority of buyers seem to be recreational drug users who have used drugs previously. They are attracted to the cryptomarkets to purchase drugs because of a perceived increase in safety, improved quality and variety, and ease and speed of delivery.

- Buyers tend to base their purchases on:

orice

$\because \equiv \equiv$ details of products available 'trip reports' (descriptions of personal experiences with the effects of specific substances)

vendor reputation feedback from

other buyers

- More than half of the vendors made more than $\$ 1,000(€ 877.2)^{*}$ per month and the most

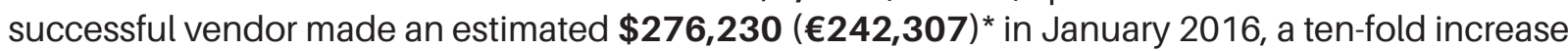
on the most successful vendor in 2013.

- Cryptomarkets are dominated by vendors who tend to specialise in drugs only, which is particularly the case for Dutch vendors.

\section{Share of vendors by type of merchandise (\%)}

All vendors

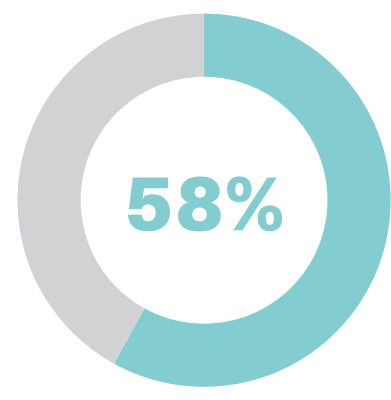

Vendors who sell drugs and nothing else
All vendors

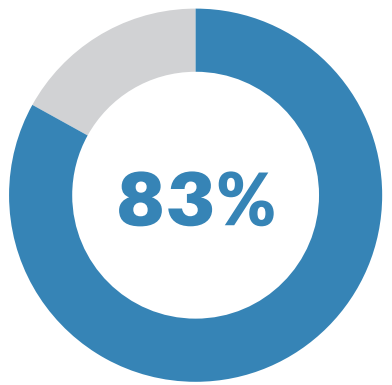

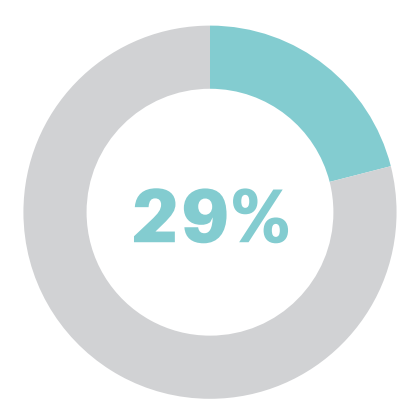

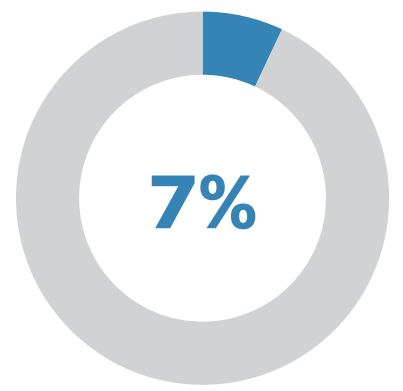

Vendors who sell anything but drugs

- Vendors have creatively adjusted their behaviour to avoid detection, such as changes in shipping practices.

- There has been an emergence of single-vendor markets on the 'dark web', i.e. web shops that are run by one vendor only. 


\section{Modes of detection and intervention}

The study identified four broad potential strategies that have been used law enforcement agencies in the detection and intervention of the Internet-facilitated drugs trade:

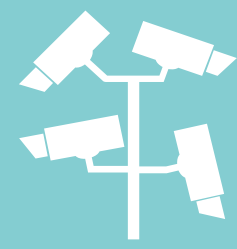

1. Traditional investigation techniques applied in the drug chain (e.g. surveillance, undercover operations).

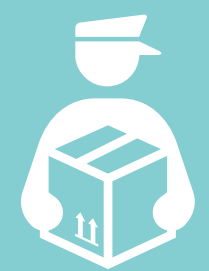

2. Postal detection and interception (e.g. collaboration between law enforcement agencies and postal services).

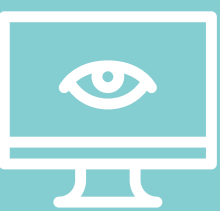

3. Online detection (e.g. big data techniques, monitoring of online marketplaces, tracking money flows).

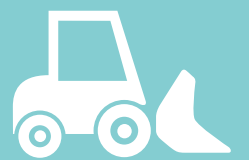

4. Online disruption (e.g. taking down online marketplaces).

In addition, international cooperation and coordination (and the accompanying legal challenges), capacity and resources, and (technical) capabilities could play a facilitating role in deploying the different strategies to tackle the Internet-facilitated drugs trade. 


\section{The impact of the 'dark web' on the illicit drugs trade}

Although individual cryptomarkets tend to have a relatively short life span, the sector as a whole has survived various challenges, such as exit scams and law enforcement take downs. At the same time, although the size of the drugs trade via cryptomarkets is still very small compared to offline trade, transactions have tripled since the take-down of Silk Road and revenues have doubled. The Internet has offered opportunities for drug entrepreneurs to create new business models and tap into a new consumer base, while reducing many of the risks associated with offline markets (e.g. violence), and introducing new risks (e.g. postal interception, scams).

The full impact of the Internet-facilitated drugs trade on the global market for illicit drugs remains inconclusive and unclear. There is evidence to suggest that cryptomarkets are fuelling offline markets for illicit drugs, but more work is required to fully understand the extent to which buyers of drugs online are distributing them offline. Finally, there are different arguments about the societal impacts of cryptomarkets. Some have argued that they actually reduce violence from the drug supply chain, which could be seen as a positive benefit. However, others believe that, by offering a new, often young, consumer base easy access to drug markets, cryptomarkets have largely negative consequences.

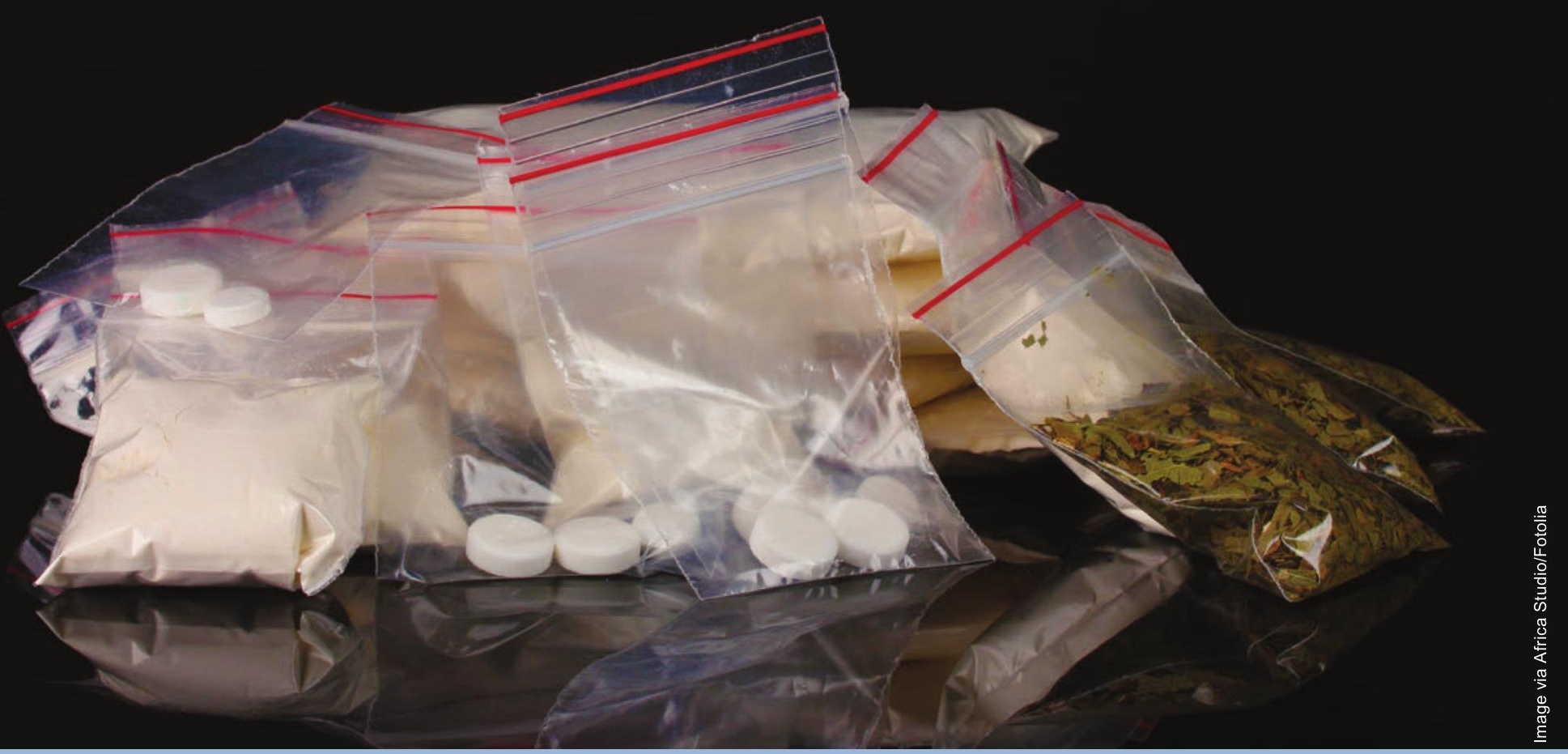

*The values are based on EUR/USD exchange rate of 1.14 as of April 2016

Cover image shared by Jo Naylor via Flickr; CC BY 2.0.

This summary describes work done by RAND Europe documented in Internet-facilitated drugs trade: An analysis of the size, scope and the role of the Netherlands by Kristy Kruithof, Judith Aldridge, David Décary-Hétu, Megan Sim, Elma Dujso and Stijn Hoorens, RR-1607-

WODC, 2016 (available at www.rand.org/t/rr1607). To view this summary online, visit www.rand.org/t/rb9925. RAND Europe is a not-for-profit organisation whose mission is to help improve policy and decisionmaking through research and analysis. RAND Europe's publications do not necessarily reflect the opinions of its research clients and sponsors. RAND ${ }^{\circledR}$ is a registered trademark. 